\title{
La exclusión del otro desde la elite y el Estado
}

\author{
Angela Boitano G. \\ Facultad de Ciencias Sociales e Historia, Universidad Diego Portales, \\ Santiago de Chile \\ Email: angela.boitano@udp.cl
}

Resumen: El diálogo fallido entre Estado y pueblo mapuche se enraíza en la formación misma del Estado chileno promovido por una elite que construye una institucionalidad a su imagen y semejanza, ilusamente homogénea e invisibilizadora de las diferencias. No obstante, el mismo espíritu “civilizador” que espera integrar a estas minorías asimilándolas, facilita la inserción de estas minorías en el diálogo postmoderno acerca de la interculturalidad, en el cual se enfrentan a la perspectiva multiculturalista que no da cuenta del acto de reconocimiento que implica convivir con la otredad.

Palabras clave: Estado; elite; hegemonía; exclusión; intelectual indígena; multiculturalismo; interculturalismo.

\section{The exclusion of the other coming from the elite and the State}

\begin{abstract}
Between the Chilean state and the Mapuche people there is a deep-rooted lack of dialogue, which is related to the formation of the Chilean state. The Chilean state was produced and imposed by the Chilean elite. The Chilean elite modeled the state based on its own self-image, as homogenous and civilizing. Therefore differences with the Mapuche people were made invisible. Similarly, the Chilean state sought to assimilate the Mapuche people into the Chilean society because of its "civilizing” spirit. However, the same civilizing spirit eventually made it possible for the Mapuche people to engage with the Chilean state in a postmodern exchange thanks to interculturalism. Currently the Mapuche people challenge multiculturalism -favoured by the Chilean stateas it does not account for the act of recognition involved in living with the otherness.
\end{abstract}

Keywords: State, elite, hegemony, exclusion, mapuche intelectual, multiculturalism, interculturalism.

\section{A exclusão do outro desde a elitee o Estado}

Resumo: O diálogo falho entre o Estado e o povo mapuche está enraizado na própria formação do Estado chileno promovido a través deuma elite que constrói uma institucionalidadeà sua imagem e semelhança, falsamente homogênea e invisibilizadoura das diferenças. No en tanto, o mesmo espírito "civilizador” que aspira a integrar essas minorias assimilando-as, facilita a inserção dessas minorias no diálogo pós-modernosobre a interculturalidade, em que se confrontam à perspectiva multiculturalista que não toma conta do ato de reconhecimento que implica viver com a alteridade. 
Palavras-chave: Estado; elite; hegemonia; exclusão; intelectualindígena; multiculturalismo; interculturalismo.

$* * *$

\section{Introducción}

En este ensayo se aborda una reflexión en torno al diálogo fallido entre el Estado chileno y la Nación mapuche, el que, desde los años 1990 hasta ahora, adquiere las características de un conflicto social intenso y violento. Este fracaso no sería casual sino que estaría entretejido en la arquitectura que construye y diseña la elite chilena fundada sobre la hegemonía social que impone como grupo. Esta elite del siglo XIX es un poderoso y dinámico promotor de la constitución del Estado, en cuyo origen se encuentra la marca de la exclusión de todo aquel considerado otro, léase: no miembros de la elite, es decir, pertenecientes a otra clase social o a otra etnia. Esta elite se vincula socialmente mediante lazos tanto familiares como económicos, siendo difícil hasta ahora delimitar claramente donde comienza uno y termina otro (Correa 2011). Este grupo privilegiado se autodefine como homogéneo tanto cultural como étnicamente y en consonancia con esta autoimagen construye un Estado a su semejanza (Samaniego y Ruiz 2007), con el que se pretende borrar las diferencias étnicas y culturales o al menos invisibilizarlas. Pero como toda lógica represiva produce su síntoma, se gesta en su seno un movimiento reivindicativo animado este último tiempo por el discurso renovado de grupos de intelectuales mapuche. La elite en su vertiente liberal se enfrenta a las demandas indígenas apropiándose de un discurso de derechos individuales y universales que hoy se inscribiría bajo el alero del multiculturalismo. Esa sería la fórmula bajo la cual se acepta a este otro tradicional e históricamente negado versus un enfoque intercultural que lo supera.

Se contextualiza esta reflexión en el marco de la re-etnificación de las demandas por justicia que se advierte en América Latina desde comienzos de los 1990 (Bengoa 2007), poniendo en tensión las aspiraciones universales a la libertad y la autonomía ${ }^{1}$ y el particularismo que supone posicionarse como indígena. Mientras el universalismo pretende borrar las diferencias raciales, de clase, de género, el particularismo las restablece (Boitano 2010). El ensayo muestra que el conflicto actual entre estado chileno y pueblo mapuche es de larga data y se sustenta en la construcción de un Estado ciego a las diferencias y en una valorización de la homegeneidad étnica como signo civilizatorio. Se estructura en tres partes. En la primera, se analiza el modo en que se construye el Estado chileno por parte de una elite. Luego, en la segunda parte se abre una reflexión en torno al valor de la homogeneidad como el pilar que fundamenta la exclusión. Finalmente, la última parte del ensayo se centra en el modo en que las democracias liberales recepcionan las demandas por justicia que se han etnificado. 


\section{Origen de la exclusión}

La elite chilena del siglo XIX se caracterizó por su decisivo rol en la configuración del Estado y por su -hasta ahora- intrincado vínculo con el poder, tejido por la actividad que emprende en áreas clave de la economía (agro, industria, minería y comercio) y por sus relaciones de parentesco mediante las cuales se reproduce socialmente y excluye sistemáticamente, con todos los medios que tiene a su alcance, a sus otros no-significativos ${ }^{2}$. Para comprender la relación conflictiva entre el Estado y el pueblo mapuche hay que distinguir tres grandes períodos en la historia de la resistencia mapuche: uno marcado por la guerra abierta entre diversas comunidades disgregadas que ocupaban desde el Río Limarí hasta el Toltén y el ejército español, que dura por lo menos un siglo a partir de la llegada de los primeros conquistadores hacia 1535; otro período en que, luego de 100 años de guerra, la Corona española reconoce formalmente a las autoridades mapuche como interlocutores válidos, mediante la firma del Tratado de Quilín en 1641, produciéndose entonces un período de paz, inestable pero fructífero; y un tercer momento en que se renueva la relación conflictiva, ahora con el Estado chileno, que en su misma constitución se plantea como homogéneo étnicamente.

Este ensayo se enfoca específicamente en este último período, enfatizando que la historia de exclusión y dominio de la que es objeto el pueblo mapuche por parte del Estado no es un hecho aislado, sino un tratamiento inhumano que se sustenta en relaciones de poder y en ideologías racistas (Todorov 2005: 115-155). Posteriormente a la Independencia chilena, a comienzos del siglo XIX, el trato que se da al pueblo mapuche sufre un cambio radical:

En 1810, hispanos y mapuche vivían una suerte de Pax obtenida por la hábil gestión política de un europeo no español, Ambrosio O’Higgins, quién habría suprimido las encomiendas y dado un nuevo lineamiento a la política de parlamentos ${ }^{3}$. Pero además el hijo del gobernador y otros próceres, adoptaban los símbolos mapuche, para emanciparse del yugo borbónico. Los patriotas "soñaban" a los mapuche como héroes y se presentaban en los salones, festejando el amanecer del nuevo Estado, revestidos del heroísmo del antiguo Arauco (Samaniego y Ruiz 2007: 17).

Pero esto duraría poco. Tal como señala Marimán (2006), se adopta entonces un molde cultural, lingüístico, jurídico y religioso homogéneo que termina por derribar todos los “acuerdos" suscritos entre españoles y mapuche entre 1641 y 1803. Los años 1862, 1878, 1881 y 1883 marcan hitos en que el Estado chileno adelanta la línea de frontera, llevando finalmente a los mapuche a vivir en pequeñas extensiones de tierra de propiedad común, conocidas como "reducciones"4. El trato que el Reino de España dio a los indígenas en los siglos XVI al XVIII, de socios comerciales, se transforma bajo la conformación del Estado-nación en una relación de dominación abierta y conflictiva. Correa y Mella (2010: 41) señalan que, ya en el año 
1852, “el discurso de la hermandad que levantaron los 'Padres de la Patria' está llegando a su fin, y si en algún momento se habló de la heroica Araucanía, ahora se habla de la degenerada raza que la habita”.

Marimán (2006) parece concordar con muchos otros autores, en que la independencia tuvo ciertamente motivaciones económicas, pero que esas razones no explican la arremetida contra los mapuche de la manera violenta en que se realizó. Todorov $(2005,2007)$ sustenta la idea de que la dominación de los indígenas americanos no puede ser explicada si no se atiende a una ideología que ordena el mundo jerárquicamente y que se acompaña de una categorización que ubica a unos -los conquistadores, europeos- en el lugar de poder-saber y otros -los indígenas- en un lugar subalterno. En particular, esta representación que se forma en el mundo hispano criollo acerca de los indígenas está sustentada en la idea de superioridad racial. Marimán señala al respecto:

Cabe recordar aquí que los criollos étnicamente son europeos, la diferencia con los llamados hispanos fue su condición de haber nacido en América o ser hijos de criollos, por lo que los mestizos de indígena, negro u otra categoría subalterna no pertenecían a este estamento étnico o racial (Marimán 2006: 81).

Esta representación de los mapuche se transforma y transita desde el concepto que designa lo desconocido para los primeros conquistadores, a saber: indio, que inicialmente hace justicia a la mirada del extranjero que establece una relación de homonimia entre la especie extraña y el "lugar", pasando por guerreros indómitos, y hasta agregársele hoy a la categoría de terrorista (Correa y Mella 2010; Saiz, Rapimán y Mladinic 2008). Coherentemente, Todorov (2005) diría que la denominación acerca del otro nunca está desprovista de valoración. Como señala este autor, ya en los siglos XVII y XVIII en Europa -en Francia particularmente-, se reflexionaba en torno a la diversidad de pueblos y razas, discusión que se centra en tres grandes temas: la oposición entre juicios universales y relativos, las razas, la nación y la nostalgia exótica, pero -advierte Todorov, y ésta es la tesis de su trabajo- se trata en definitiva de ideologías, pues -señala- "hablo no de las razas en sí, ni de los comportamientos racistas, sino de las justificaciones que les fueron dadas” (Todorov 2005: 15). Son efectivamente las doctrinas sobre la raza y sus explicaciones que se escudan en argumentos más o menos metafísicos -primero- y -luego- científicos, los que permiten explicar que el maltrato a los otros considerados inferiores es un acto posibilitado por ciertas ideas y representaciones que permiten que los actos, por repudiables que sean, terminen siendo aceptados como si fueran naturales. El mismo autor lo señala en "La conquista de América" (2007), que no fue ésta promovida solamente por un afán de expansión económica, sino además por una idea acerca de sí-mismo como portador de civilización y verdad.

La elite se nutre de ideas provenientes de Europa y comparte una situación económica próspera en comparación con la que experimentan sus 
trabajadores en la hacienda, conformados por negros, mestizos e indígenas. Parte de las ideas emancipatorias de las que se inspira esta elite es un moderno discurso de derechos que se aplica a sus intereses independentistas respecto de la Corona española, pero que no se extiende a sus propios modos de considerar lo cultural y étnicamente diverso. Es así que se configura un universo de distinciones que se caracteriza por una porfiada valoración de lo homogéneo y ordenado como lo correcto y civilizado, que requiere de la represión o, por lo menos, la invisibilización de la etnicidad -que representa lo incorrecto, lo salvaje e incivilizado-. Esas serían las funciones que cumplen la reducción a espacios delimitados y el dominio lingüístico mediante la escolarización universal ${ }^{5}$. Esto no es casual ni propio sólo de esta relación. Bengoa (2006, 2007) y Salazar y Pinto (1999) señalan que los Estados tienden a privilegiar la vinculación del poder político con una sola nación o etnia ${ }^{6}$, negando la existencia de otras comunidades culturales en su territorio o promoviendo su rápida asimilación.

Resultado de esto es que a las minorías se las condena al silencio o a la impotencia. Un buen ejemplo de esto es la revisión que hacen Correa y Mella (2010) de los reclamos por tierras que formulan los mapuche, la mayoría de ellos inconducentes. Citan una de estas formulaciones en que las familias de Tricauco plantean:

El cementerio estaba en tierras muy antiguas de la comunidad en tiempos muy antiguos. En ese cerrito de Poluco, si uno escarba encuentra cantaritos y esas cosas. Con eso nosotros justificamos que esa tierra es de nosotros. Los mapuche antiguos dijeron que las marcas eran dos cerros, e incluso hay una marca, hay una piedra que marcaron los viejos, hicieron una pata de mula, cuánto habrán trabajado esos viejos para hacer esa marca, y todavía está. Nosotros colindamos con Quechereguas, con los Aniñir. Los deslindes antiguos no tienen nada que ver con los que hay ahora, el deslinde del verdadero territorio de Tricauco era el rio Huequén con Poluco, colindando con Quechereguas. Los lonkos antiguos se respetaban por el río. Los de Chequenco nunca pasaron por acá, ni los Tricauco pasaron por allá (Correa y Mella 2010: 154).

Los reclamos de los mapuche se formulan sin autoridad y es evidente el enfrentamiento a actores que sí son capaces de producir una definición del mundo social. Se produce además una tensión entre discursos: uno moderno de derechos individuales versus uno basado en la legitimidad de derechos comunitarios. El primero sustentado en una concepción abstracta e igualitaria de ciudadano (bajo la metáfora del mercado), que se impone a un grupo cuyo discurso lo ubica en un lugar que no está autorizado para hablar ni para decir cómo son las cosas, pues su lengua y su modo de pensar no se ajustan al ritual de la institución que reconoce como legítimos ciertos discursos y una manera de expresarse respecto de sus reclamos (Bourdieu 2008: 99). Esta desigualdad se verifica sobre todo en la historia de pérdida de tierras que tiene lugar básicamente hasta los años 1960, que coincide con la Ley de Reforma Agraria y los posteriores logros que alcan- 
zan su punto cúlmine con el gobierno de Salvador Allende, los que rápidamente se revierten en dictadura (1973-1990) ${ }^{7}$.

La dominación del pueblo mapuche se termina de sellar con la imposición de una lengua oficial en la que se desarrolla la vida pública, la educación, la justicia, los medios de comunicación, etc. cuestión íntimamente vinculada a la consolidación de un Estado y, en el caso de Chile, además, a la hegemonía de una clase social. Bourdieu (2008: 23) señala que "la integración en una misma 'comunidad lingüística', que es un producto de la dominación política, reproducido sin cesar por instituciones capaces de imponer el reconocimiento universal de la lengua dominante, es la condición de la instauración de las relaciones de dominación lingüística”, pues con ese acto se oficializa un uso -generalmente escrito y culto- y se devalúan otros vinculados a modos de vida menos cultos o sencillamente orales. Asimismo, los usos diferenciales permiten construir categorías de personas. En efecto, cuando se oficializa una lengua "no sólo se trata de comunicar, sino de imponer un nuevo discurso de autoridad, con un nuevo vocabulario político, términos de referencia, metáforas, eufemismos y la representación del mundo social [...]” (Ibíd.: 26). Se oficializa una lengua estándar, ciertamente más inclusiva de las mayorías y excluyente de las hablas locales que deben adaptarse para acceder al diálogo racional propio de las prácticas modernas, o quedar excluidas.

Se construye de esa manera el terreno sobre el cual se desarrollará el conflicto entre diferentes grupos y cosmovisiones. El Estado produce categorías de personas, entre esas la del marginal, el otro, el desviante. Muchas veces, la "integración” que se ofrece a las minorías étnicas que quedan subsumidas bajo un Estado es la homogeneización, que implica a sus miembros transformarse en ciudadanos con las consecuencias a veces negativas que eso supone. Así fue como los mapuche debieron adoptar identidades devaluadas o, en el mejor de los casos, incongruentes, tanto con el lugar simbólico que ocupan dentro del Estado como con las capacidades materiales con que cuentan para desenvolverse en éste como ciudadanos en igualdad de condiciones.

Finalmente, el conflicto del presente se ha tejido mano a mano entre muchos actores, ninguno de los cuales se hace cargo de la responsabilidad que le cabe -sino en el origen- al menos en el agravamiento y la perpetuación de este conflicto. Caniuqueo (2006: 130) señala que una causa que explica la situación de conflicto a la que hemos llegado es: "no centrarse en lo propio, puede ser la siutiquería latinoamericana, la cual está estrechamente relacionada con las estructuras cognitivas del colonizador, basado en un sistema neocolonial a la europea”.

\section{El valor ambivalente de la homogeneidad}

Para fines de este ensayo no se profundizará en las derivas que ha experimentado la elite chilena, que en el siglo XIX es protagonista de la 
formación del Estado y sus principales instituciones económicas, hasta hoy; sólo resta decir que la elite ha sido dinámica y flexible para adaptarse a los desafíos que se le han presentado. Correa (2011) señala que esta elite no se transforma en "derecha" sino hasta 1930 aproximadamente, cuando surgen fuerzas antagónicas con proyectos de sociedad alternativos, vale decir cuando surge una "izquierda".

Siguiendo una tradición decimonónica, también en el siglo XX la clase dirigente que hundía sus raíces en el siglo XIX, se expresó en dos partidos políticos, el Partido Liberal y el Partido Conservador. Ambos se diferenciaban fundamentalmente por el factor religioso, lo que tenía repercusiones tanto en su estilo como en sus estrategias, por lo que la expresión de la derecha en dos partidos tuvo sentido. Ello, no obstante eran más importantes los elementos que los unían que los que los separaba, pues tanto liberales como conservadores representaban a la elite decimonónica y, en general, a los partidos propietarios. Ciertamente, esto se traducía en un acuerdo en cuestiones básicas, como la defensa de la propiedad privada, la limitación de las atribuciones estatales, la necesidad de controlar el movimiento sindical y un fuerte anticomunismo (Correa 2011: 64, las negritas son de mi autoría).

Estas cuestiones básicas, es decir aquello respecto de lo cual no se discute, son el piso sobre el cual se toman muchas decisiones que afectan a las grandes mayorías, y con mayor razón a aquellas minorías no representadas. La institucionalidad que se ha construido no tiene capacidad de recoger las demandas de los otros y ha producido modos de vida altamente segregados en que el encuentro recíproco con el otro es casi imposible, eso sin mencionar los altos índices de desigualdad que exhibe nuestra sociedad. Entre los factores que reproducen esta segregación social, se encuentra la progresiva "elitización" de aquellos que ejercen el poder en Chile (Espinoza 2010), cuestión que probablemente explica el trato sistemáticamente invisibilizador de las diferencias que se ha dado a los mapuche hasta hoy. Prueba de ello es que los miembros de las elites políticas de hoy, cualquiera sea el sector al que representan, provienen cada vez más de sectores sociales muy homogéneos y han sido educados mayoritariamente en establecimientos privados. Eso es importante destacarlo, pues la diferencia se construye en un sistema de distinciones, en este caso "nosotros" y los "otros" se bosquejan en el suelo común de la pertenencia a los mismos grupos.

El valor de lo homogéneo podría estar vinculado a las aspiraciones emancipatorias relacionadas con la igualdad, y en ese caso a la ampliación de la democracia. O puede tener su lado oscuro y producir la consecuencia perversa de que el valor de la igualdad termine por construir la experiencia de un grupo como si fuese ésta el paradigma del ser humano y eso oscurezca las diferencias. Es lo que profundiza Benhabib (1990) al hacer la crítica de la noción de individuo autónomo, desvinculado, racional de las teorías universalistas del contrato, que se conceptualiza como self desincardinado 
y desarraigado ${ }^{8}$ produciendo la exclusión de toda aquella experiencia que no refleje al otro generalizado (que es masculino, occidental, urbano, de cierta clase, educado, etc.), gesto con el cual quedan excluidas las mujeres, los pobres, los indígenas, en síntesis: las minorías subordinadas, con todo su mundo significativo.

Taylor (2003) señala que esto es propio del Estado moderno que necesita de esta homogeneidad, razón por la cual difunde y oficializa una cultura y una lengua, como un imperativo funcional. Es la manera como "la red de identidades, vinculada a la familia, al clan, a la localidad y a la procedencia, tiende a declinar, y adquieren una creciente importancia las nuevas identidades ‘categoriales' que nos vinculan a una multitud de otros” (Taylor 2003: 55-56). Frente a este modelo, no todas las minorías reaccionan de la misma manera; algunas se integran a la reestructuración, otras resisten. Es el caso de los mapuche cuya resistencia se basa en un modelo de legitimidad democrática que exige que las leyes que gobiernan a los pueblos sean resultado de decisiones colectivas. Precisamente es lo que se encuentra en entredicho en este caso: se reclama el derecho a ser reconocidos como pueblo y a que su voz sea escuchada en un diálogo del cual se derivan decisiones que tienen consecuencias para la vida significativa de estas minorías.

La igualdad que ha defendido la elite chilena se parece más a una porfiada idea acerca de Chile como un país homogéneo y estable, que puede ser visitado y donde se puede invertir sin mayores preocupaciones, porque es predecible y ordenado -un valor caro a la derecha conservadora-. El énfasis en la homogeneidad cultural y étnica del país y la identificación con "lo europeo" - guiño al conquistador- es refrendada por los discursos que se producen a propósito del primer centenario de Chile. Samaniego y Ruiz (2007: 33) señalan:

Desde mediados del siglo XIX, la imagen que el Estado chileno quería proyectar hacia el extranjero, con vista tanto a fomentar la emigración selectiva de europeos como la inversión extranjera, era la de un país sin indígenas. Subyacía en ello la concepción de que, una nación racialmente homogénea, cuya población sería europoide, carece de conflictos interétnicos y pertenece a un mundo civilizado.

Lo que termina por consolidar esta homogeneización cultural -porque la destrucción de la vida comunitaria fue parte de una estrategia más económica, aunque con profundas consecuencias para el modo de vida- es la imposición de una educación formal universalizante que deja fuera la noción de interculturalidad. Esto produce la pérdida paulatina de la lengua, al menos en la esfera pública, e introduce estereotipos de héroe y villano que terminan por aculturar a los miembros más jóvenes del pueblo mapuche. La contracara de este proceso es que el mismo espíritu que conceptualiza a la escuela como un aliado en la tarea de civilizar a los indígenas, se transforma en un instrumento de resistencia. Pues, el acceso formal y masivo a la educación formal es lo que ha permitido - a la larga- la formación de grupos 
importantes de intelectuales indígenas desde aproximadamente la segunda mitad del siglo XX. Al respecto, Zapata (2005: 71) señala:

La modernización latinoamericana no ha sido un proceso homogéneo ni alejado de las contradicciones, pero para efecto de nuestro estudio enfatizaremos aquellas tendencias democratizadoras que marcaron el inicio de una sociedad de masas en la primera mitad del siglo XX. Así, el acceso a la educación nos parece que es el hilo conductor que permite rastrear el surgimiento de una elite indígena integrada por profesionales de distinto tipo, de la cual se desprenderán los intelectuales indígenas.

Los intelectuales mapuche ${ }^{9}$ de hoy han sido socializados en comunidades indígenas -o en relación con éstas- que han experimentado profundas modificaciones en sus modos tradicionales de vida, producto de conflictos con empresas forestales y del rechazo a proyectos energéticos en territorios considerados como sagrados para los indígenas. Finalmente, esta generación se ha escolarizado, ha adoptado modos de vida urbanos, ha visitado otros países, se ha insertado paulatinamente en la academia y a diversos proyectos intelectuales; todo lo cual contribuye a que la significación que otorgan a su identidad mapuche sea reformulada y se desplace desde lo tradicionalmente valorado del espacio comunitario, local, particular y privado, hacia el espacio global, universal -expresado en el discurso emancipatorio de derechos- y político de lo público.

En este desplazamiento, se recogen experiencias de vida, aceptación de corrientes teóricas y metodológicas con que se reinterpretan los procesos históricos de despojo y colonización, la situación colonial y las recomposiciones del colonialismo ${ }^{10}$. Es posible incluso que aquel relato, formulado para dar sentido a una resistencia política, dialogue mejor con el discurso de derechos que se enuncia desde los lugares de poder (pues ambos ya están resignificados). Es probable que combine una perspectiva comunitaria de la identidad con una noción individualizada sostenida por la ciudadanía homogénea que impone el Estado. Ahora bien, un discurso más universal y "dialogante" no implica necesariamente llegar a consensos, pues no es desde una perspectiva habermasiana que se comprende esto. Dialogante significa sencillamente que las partes se ubican en el mismo terreno en que se produce la disputa, asumiendo que la discusión es política, es decir, "de poder”. Se debate este tema en la última parte de este texto.

\section{El gesto $^{11}$ del multiculturalismo}

Hemos dicho hasta ahora que es una elite la que promueve la formación del Estado chileno, razón por la cual éste se construye desde una perspectiva homogénea que no sólo invisibiliza las diferencias sino que además las desvaloriza. Habría que agregar que, en este afán civilizador y auto centrado, se fomentó la asimilación, definiéndose como universal el paradigma de ser humano europeo. En este contexto, la educación formal 
cumplió un rol “civilizador” fundamental (Donoso 2008; Foerster y Montecino 1988), pero que no borró la diferencia que posicionó al indígena como otro. Esto último es importante si consideramos que es desde la perspectiva multiculturalista ${ }^{12}$ que hoy se enfrenta la demanda por reconocimiento de las diferencias.

El multiculturalismo resulta problemático respecto de cómo enfrenta la diferencia cultural y cómo concibe a la cultura misma. Kymlicka (1996: 112) define la cultura societal como "formas de vida significativas a través de todo el abanico de actividades humanas, incluyendo la vida social, educativa, religiosa, recreativa y económica, abarcando las esferas pública y privada [...], que tienden a concentrarse territorialmente, y se basan en una lengua compartida”. En efecto, se concibe a la cultura como una totalidad relativamente fácil de delimitar, congruente con un grupo humano cuyo relato identitario es compartido y no tiene fisuras. Es lo que Benhabib (2006) ha criticado bajo el concepto de "sociología reduccionista de la cultura" o "trampa del esencialismo culturalista”, frente a la cual propone una perspectiva que comprenda el carácter binario del concepto de cultura, que comprendería un registro práctico (relatos del hacer) y el relato narrativo (que supone una actitud normativa hacia los relatos de acciones) que se construiría siempre controversialmente. Tal como lo afirma esta autora, las culturas societales que define Kymlicka sencillamente "no existen" (Benhabib 2006: 112), pues éstas nunca son homogéneas. Por el contrario, estarían formadas por relatos contradictorios y fluidos, dinámicos y cambiantes; por otra parte, tampoco serían siempre institucionalizadas, sino que muchas veces suelen ser informales e incluso amorfas.

Otro problema se refiere a cuánto de otredad efectivamente está dispuesto a tolerar el liberal (Zizek 2004), sobre todo si se piensa en que muchas veces cuesta hacer legítima una defensa de derechos específicos para aquellos grupos que violan los derechos de sus miembros. Esto ha puesto en tensión el multiculturalismo con formas específicas de demandas minoritarias, como el feminismo. Según Kymlicka (1996), esto es un asunto de tiempo, pues casi todas las sociedades liberales habrían comenzado siendo iliberales, por lo tanto, la apuesta sería a liberalizar las culturas societales. Entonces, la propuesta apunta a aceptar la legitimidad de los derechos especiales sólo a aquellos grupos en que no se violen los derechos de sus miembros, es decir, se espera que estos terminen adaptándose a las normas de la sociedad liberal en que están insertos. Y esa es ciertamente una distinción muy etnocéntrica, pues se tolera al otro mientras no toque alguna dimensión especialmente importante para los "tolerantes" liberales, a saber: las libertades individuales, la propiedad privada, etc. Mientras tanto mientras se sigan comportando como "fundamentalistas"- se los acepta bajo un enfoque "preservacionista” (Benhabib 2006: 123).

En efecto, si no aceptamos la otredad con todo lo que ello implica, el multiculturalismo se transforma en una mera tolerancia que encubriría cierta hipocresía, en tanto se mal acepta a otro pero ya reducido, o descafeinado, como diría Zizek (2003): 
¿Se acepta al otro? Siempre y cuando se trate solamente de una cuestión de alimento, cultura, danzas. ¿Y la extirpación del clítoris? [... ¿QQué hay de esa antigua costumbre india según la cual, cuando un hombre muere hay que quemar a su esposa con él? ¿ंRespetamos eso? Aquí surgen los problemas.

Taylor (1997) aborda este tema cuando hace una crítica a la supuesta neutralidad valórica del liberalismo. Señala que la sociedad liberal no es en realidad un punto de encuentro entre todas las culturas, sino la expresión política de un sector, incompatible frecuentemente con otros grupos minorizados. Al respecto, afirma Levil (2006: 245) que:

Se ha reconocido que la globalización no es un fenómeno neutro que valide todas las formas culturales bajo un prisma de relativismo multiculturalista, sino que por el contrario, más bien constituye el vehículo de expansión de un modelo ampliamente reconocible y que tiene que ver con la racionalidad productiva del libre mercado y la ciencia. En cualquier caso tenemos un modelo cultural con pretensiones hegemónicas y con los medios y los dispositivos para ejercer esa hegemonía.

En efecto, el liberalismo no es neutral en términos culturales, y esto tendría consecuencias prácticas, no sólo en relación con la cuestión de la sobrevivencia de una cultura diferente, sino también en el modo en que se reconoce su valor y qué de esa expresión o modo de vida peculiar se valora (Taylor 1997). El liberalismo hegemoniza una serie de significantes caros al mundo occidental, tales como autonomía, sí mismo-otro, individualidad, etcétera, bajo el significado de libertad. Se naturaliza así el concepto de libertad del liberalismo, haciendo opaco el espacio pre-construido discursivamente que permite que se defina libertad de "esa" manera y no de otra, como si fuera ésta la única concepción. No hay libertad como tal, en sí misma, o fuera de un sistema de diferencias. Es en la relación entre elementos desde donde se configura finalmente esta definición, y esta "libertad" no es más -ni menos- que la libertad del mercado, en donde los individuos se sitúan idealmente en igualdad de condiciones en vistas a la transacción de bienes de diversa índole.

Y finalmente, esta última controversia deja ver otra aún más soterrada, aquella que se relaciona con la insistencia del multiculturalismo en conceptualizar los movimientos sociales como fragmentarios, descuidando el análisis del sistema como totalidad articulada en que el capitalismo opera como telón de fondo, dejando intacta esta homogeneidad básica del sistema mundial que instala el capitalismo. Es la crítica que formulan Jameson y Zizek (1998) cuando señalan que la excesiva atención a la diferencia hace escurridiza a la mirada atenta el trasfondo del capitalismo salvaje que atañe a todos.

Por todas estas razones, el multiculturalismo es un gesto, una mueca, pero no un acto de reconocimiento de la otredad pues se sustenta en la 
idea liberal del mercado como metáfora de la vida social, espacio en el cual los individuos son iguales y transan bienes y valores en igualdad de condiciones, o al menos nada se los impide: la libertad negativa del liberalismo. Desde esta perspectiva no hay "otro", solo habría individuos que no han sabido usar bien o eficientemente su libertad. Este sólo sería posible si el Estado de Chile reconociera al pueblo mapuche como una nación originaria portadora de derechos, entre los cuales se encuentra el de ocupar un territorio históricamente determinado (Levil 2006).

Una alternativa al multiculturalismo es la perspectiva intercultural que amplía el horizonte hacia la comprensión de "una experiencia cotidiana de estar en contacto con el otro, de concebir la cultura como proceso de 'comercio' con lo ajeno" (Fornet-Betancourt 2002: 127) en que surge "lo propio" en el marco de una comunidad en litigio y conflicto. El interculturalismo implica la superación del pensamiento de la multiculturalidad, que acepta la coexistencia y convivencia de minorías culturales con la condición de que sean liberales internamente en el trato dado a sus minorías. La interculturalidad no sólo propone el reto de reconocer las diferencias y permitir la coexistencia de minorías diversas, sino que asume como elemento central la demanda hacia el Estado, en el sentido de que se espera de éste que garantice la inclusión mediante políticas diferenciadoras. Esto en el contexto de las crisis de las políticas homogeneizantes y uniformadoras cada vez más incapaces de responder a la creciente diversidad de las naciones plurales, que en Latinoamérica se relaciona más con la mayor visibilidad que adquieren los movimientos de minorías étnicas que con un aumento cuantitativo de éstas.

Concretamente, en América Latina, las minorías étnicas son la cara visible de la tradición hegemónica, son el "otro" oprimido y silenciado, producido por la conquista que destruyó y reprimió las diferencias culturales, erradicando de paso la memoria al destruir formas de vida que, sometidas a un proceso de occidentalización, quedan invisibilizadas y en el peor de los casos marginadas y devaluadas. Desde aquí surgirían prácticas de resistencia "modernas", a partir de lo que Taylor (2006: 187-188) señala como el gran cambio que se ha generado en "el modo de imaginar nuestras pertenencias”, producido por el tránsito de una sociedad jerárquica de vínculos personalizados a una menos personalizada pero más horizontal, de acceso más directo, razón por la cual se puede observar la sociedad desde una perspectiva más descentrada y más secular.

Desde la ciudadanía intercultural se pueden concebir las demandas de los movimientos étnicos como factores de democratización de toda la sociedad, pues instalan una discusión acerca del sentido de lo político, de la política y lo democrático en las sociedades nacionales en que se gestan. La cara amable de la globalización, o lo que Benhabib (2005) propone con el concepto de "globalización en reversa", es que advierte de la multidireccionalidad de los procesos. La globalización no sólo disemina corporaciones transnacionales por el mundo, sino que además los miembros de pueblos más pobres emigran hacia ciudades globales o en sus 
propios países adoptan modas, consumen bienes, se entrecruzan con gente y reciben información. En suma, el espacio público se puebla de nuevos relatos disponibles que construyen identidades heterogéneas y controversiales. La ciudadanía intercultural implica que los indígenas pueden ser ciudadanos plenos sin renunciar a su condición étnica, tampoco encerrándose en un ostracismo cultural que impida la interacción con dinámicas culturales exógenas (Del Cairo y Rozo 2006), pues se trata de que sean parte del diálogo y confrontación con “otros" sistemas políticos y culturales.

Algo se ha avanzado. Hoy, en Chile, pocas personas, públicamente al menos, confesarían su desacuerdo con la demandas territoriales que el pueblo mapuche plantea; se discutirá en torno a la cantidad, al modo en que se repara el daño, a los responsables del despojo, etc., pero de la usurpación en sí misma, como hecho histórico, no se discute. Una gramática de la redistribución señala que al pueblo mapuche le deben ser devueltas sus tierras; una gramática del reconocimiento alude a una creciente revalorización de "ser mapuche" entre miembros jóvenes y urbanos de este pueblo, a una cada vez mayor conciencia en torno a la reposición de los derechos lingüísticos, etc. Son todos discursos que pueblan la esfera pública y que se han legitimado en estos últimos años.

\section{Reflexiones finales}

Termino esta reflexión aludiendo a las paradojas que implica la constitución de todo Estado-nación. A eso hace referencia ampliamente Benhabib (2005: 49) cuando señala que:

La perversión del Estado moderno que pasó de ser un instrumento del derecho a uno de discrecionalidad sin derechos, al servicio de la nación, se completó cuando los estados comenzaron a practicar desnaturalizaciones masivas contra minorías indeseadas, creando así millones de refugiados, extranjeros deportados y pueblos sin Estado por sobre las fronteras. Los refugiados, las minorías, los sin Estado y las personas desplazadas son categorías especiales de seres humanos creadas a través de las acciones del Estado-nación.

Es esta una de las paradojas que aloja el sistema de Estados soberanos con base territorial, que aparece como el único instrumento que puede garantizar los derechos de sus miembros, aunque al mismo tiempo crea categorías de personas que quedan excluidas de estos. En el caso del Estado chileno con el pueblo mapuche, el problema no se explica por la "nomembresía” y sus consecuente pérdida de derechos, sino precisamente a un tipo de membresía que se ofrece a estos grupos minorizados que implica la devaluación simbólica y material de ellos.

Eso nos dejaría en la complicada situación de aceptar un tipo de Estado que, con sus defectos y perversiones, es preferible a que no exista; 
pues ante la ausencia de éste no se produce un vacío sino un espacio que es llenado por la lógica del mercado. Este escenario es aún peor pues no sólo no garantiza derechos sino que nos convierte en meros consumidores. Eso, claro está, si consideramos que o tenemos este tipo de Estado o no tenemos nada.

Sostengo en este punto que es posible pensar en un tipo de Estado más democrático y plural. Al respecto Marimán aporta una interesante perspectiva al historizar la noción de Estado moderno y ponerla en relación con otros contextos históricos y culturales. Desde esa perspectiva el problema no es que los Estados-nación como tales sean siempre fruto de una violencia ejercida contra otros, sino que ese ejercicio violento es posible en mayor medida cuando estas instituciones se autodefinen como uninacionales y monoculturales (cfr. Marimán 2014).

Y vuelvo al comienzo. La pregunta que animó estas reflexiones se relaciona con la preocupación por un conflicto que lejos de resolverse se agudiza y se complejiza con el paso del tiempo. Se vincula asimismo con la crítica al modo en que nuestras democracias liberales han enfrentado el problema con sus otros y espera aportar con una mirada respecto de las rutas por las que se puede transitar hacia una democracia radical y plural (cfr. Mouffe 1999), que no sólo considere en las decisiones a aquellos grupos que han sido omitidos y vulnerados históricamente, sino que los incluya en el diálogo político y como sujetos legítimos de habla, a riesgo de elevar la conflictividad en esta esfera. Transitar por esa ruta puede constituirse en la oportunidad para que se descomprima un conflicto que ha adoptado una forma violenta en una señal clara de que la palabra ha fallado. Pues finalmente, el pecado de nuestras democracias liberales ha sido no considerar seriamente la naturaleza de las identidades colectivas, lo que se traduce finalmente en su incapacidad para relacionarse con un mundo plural y con los conflictos que éste acarrea. 


\section{Notas}

${ }^{1}$ Valores caros al liberalismo que olvidan la posición diferencial de los individuos en la sociedad. Es la crítica frecuente que se hace al concepto de libertad negativa, aquella que no ejerce coacción pero tampoco facilita la plena participación de los más vulnerables, aquellos que no pueden transar en igualdad de condiciones en el mercado -la metáfora preferida que se usa para representar a la sociedad liberal- (Tugendhat 1998).

${ }^{2}$ En alusión al concepto de otro significativo (Mead 1973), cuyo reconocimiento permite a los individuos hacerse parte de un mundo social en que existen otros que tienen necesariamente vínculos de afecto con el individuo, luego -como parte de un logro evolutivo- se hace un lazo social más abstracto y basado menos en el afecto y la simpatía que en el respeto, y se reconoce a otro que legítimamente forma parte de este mundo, aunque no sea parte del mío. Se podría entonces reservar el concepto de otrono-significativo para aquel a quien, reconocido como ser humano, es categorizado como un ser inferior, al que hay que asimilar.

${ }^{3}$ Los parlamentos fueron una práctica habitual de negociación propia del pueblo mapuche. Se señala que "fueron las manifestaciones sociales de sociedades diferentes por entablar canales de entendimiento en aras de resolver sus conflictos pacíficamente [posibilitando] también las condiciones necesarias para regular lo que en los hechos se estaba dando: intercambio, negociaciones, comercio; situación que permitió a estas sociedades nutrirse de elementos culturales nuevos que terminaron por enriquecerlas bajo un clima que, si bien no estuvo exento de conflictos, proporcionó los mecanismos de regulación pacífica” (Marimán 2006: 80-81).

${ }^{4}$ Chihuailaf en "Recado Confidencial” (1999), señala acerca de las reducciones: "Y usted -seguramente- se preguntará: ¿qué significa una 'reducción’? Significa que mucha de nuestra gente fue asaltada en sus hogares, castigada, torturada, y trasladada 'relocalizada'- fuera de sus parajes habituales; o asesinada. Porque reducción, 'privatización', dicen algunos (privatizar -según el diccionario de la lengua castellana- viene de privar: Despojar de algo; prohibir o estorbar; predominar; negar), es un concepto utilizado por los Estados chileno y argentino desde mediados del siglo diecinueve, y materializado a finales del mismo. Contiene el hecho de que nuestro Pueblo fue reducido, 'reubicado', en las tierras generalmente menos productivas de nuestro País Mapuche. Ahora, a poco más de cien años de la guerra -ofensiva por parte de los chilenos y defensiva por parte de nuestra gente-, el concepto de reducción el Estado chileno lo ha encubierto en el de 'comunidad legalmente constituida'. Los sentidos son, como ve, diferentes para nuestro Pueblo y para el Estado".

${ }^{5}$ No es parte de este ensayo, pero ineludiblemente se encuentra uno con esta reflexión. A saber, que este conflicto por tierras y soberanía, por derechos de autodeterminación y trato igualitario, está acompañado de una progresiva pérdida y desvitalización de la lengua. Y sabemos que cuando desaparece una lengua, no sólo se destruye su universo de representaciones, sino todo el mundo de relaciones sociales que la caracterizan.

${ }^{6}$ Nación y etnia no son lo mismo. Habermas (2010: 108) hace esta distinción señalando que etnias son "comunidades de linaje pre-políticas, organizadas según relaciones de parentesco" y las naciones serían entidades "constituidas estatalmente, al menos aspirando a la independencia”. Ambas compartirían un núcleo común, a saber: "la 'conciencia del nosotros' fundada en el imaginario parentesco de sangre o la identidad 
cultural de personas que comparten la creencia en un origen común, se identifican mutuamente como 'miembros' de la misma comunidad y con ello se deslindan de su entorno” (Ibíd.). Para los mapuche en Chile, es central reivindicar el hecho de que son un "pueblo", no meramente una etnia, pues a pueblo le corresponde un territorio y a una etnia no necesariamente. Millalén (2006: 19) se refiere a la existencia de un Mundo Mapuche establecido claramente hacia mediados del siglo XVI y definido como "conjunto de elementos de la cultura mapuche; tanto materiales, sociales, espirituales, etc. los que organizados, relacionados y expresados en sus propios códigos, se muestra como particular y única”, todo lo cual da cuenta de la existencia de una cultura y un sistema social, bajo una unidad lingüística con sus variantes dialectales que se manifiestan hasta hoy y cuyo "horizonte cultural tiene su raíz en su espacio histórico (Wallmapu)” (Ibíd.: 28).

${ }^{7}$ Levil (2006: 233) señala: “Junto con suprimir la política indigenista y ejercer represión sobre quienes habían participado y profundizado radicalmente el proceso de reforma agraria, el régimen militar retomó desde 1978 la política de división de las comunidades mapuche, cuestión que activó la necesidad de organización [...]”.

${ }^{8}$ Los conceptos “desincardinado” y “desarraigado” los usa Benhabib en su discusión con las teorías universalistas del contrato. Desincardinado es el ser que no asume el hecho de pertenecer a un género y a un determinado tejido social que lo constituye y se presume entonces libre de determinaciones, por su parte las teoría del contrato conceptualizan así a todos los seres humanos. Desarraigado, en cambio, alude a prescindencia de la situación espacial.

${ }^{9}$ Se recomienda revisar la contribución de Zapata (2005) a esta discusión acerca del contenido del concepto de intelectual.

${ }^{10} \mathrm{Al}$ respecto, cabe señalar, como prueba de esta apertura, lo que señala Caniuqueo (2006: 209), que para reescribir la historia que se recibe del Estado chileno de manera crítica se han usado tres fuentes documentales: la II Declaración de Barbados (1977), la declaración del "Encuentro mapuche de Londres" (1978) y otra declaración hecha en Santiago de Chile en octubre de 1978.

${ }^{11}$ Gesto se considera aquí como el sucedáneo del acto en un sentido sartreano, entendiendo a éste como "una proyección del para-sí hacia algo que no es" (Sartre 1966: 540). El gesto representa al acto, pero no es aún un sostén para el ser. El acto es un motor de cambio, se toman riesgos cuando se actúa, en cambio el gesto siempre se puede refugiar en el como si. Un acto es intencional, no accidental. Y en este sentido se comprende al multiculturalismo como un gesto de reconocimiento del otro desprovisto de su otredad.

${ }^{12}$ Kymlicka es su principal portavoz. En “Ciudadanía multicultural. Una teoría liberal de los derechos de las minorías” (1996), trata este tema ampliamente. Ahí señala que el surgimiento de una "política de la diferencia cultural” representaría para algunos una amenaza a la democracia liberal, cuestión que no sería sostenible en la medida que las demandas de las minorías son consistentes con los principios liberales de libertad individual y justicia social. Agrega que -en vistas de estos principios- se torna relevante reconocer los derechos de las minorías cuando el no reconocimiento los desfavorece socialmente, les restringe libertad, etc. Advierte que estos derechos tienen límites: a) no deberían permitir que un grupo dominase a otro; b) no debieran permitir que un 
grupo dominara a sus propios miembros. Se trata de asegurar igualdad entre grupos y al interior de los grupos. Termina señalando que el futuro de la ciudadanía multicultural supone pensar a la globalización como contexto que desmitifica la idea de un Estado culturalmente homogéneo y asume los cambios de las identidades étnicas y nacionales. 
Polis, Revista Latinoamericana, Volumen 14, $N^{\circ}$ 41, 2015

\section{Bibliografía}

Bengoa, J. (2006), La comunidad reclamada. Identidades, utopías y memorias en la sociedad chilena actual, Catalonia, Santiago de Chile.

Ídem (2007), La emergencia indígena en América Latina, Fondo de Cultura Económica, Santiago de Chile.

Benhabib, S. (1990) “El otro generalizado y el otro concreto”, en Benhabib y Cornell (eds.) 1990 Teoría feminista y teoría crítica, Edicions Alfons el Magnánim, Generalitat Valenciana (Ed. Benhabib y Cornell), Valencia.

Ídem (2005), Los derechos de los otros, Gedisa, Barcelona.

Ídem (2006), Las reivindicaciones de la cultura: igualdad y diversidad en la era global, Katz Editores, Buenos Aires.

Boitano, A. (2011), “Demanda mapuche: tensión entre identidad y diferencia, ciudadanía y comunidad, particularismo y universalismo”, en Polis, Universidad Bolivariana, Santiago de Chile, Vol. 10, N² 28, pp. 307-321.

Bourdieu, P. (2008), ¿Qué significa hablar? Economía de los intercambios lingüísticos, Akal, Madrid.

Butler, J. y Spivak, G. C. (2009), ¿Quién le canta al estado-nación?, Paidós, Buenos Aires.

Caniuqueo, S. (2006) “Siglo XX en Gulumapu: de la fragmentación del Wallmapu a la unidad nacional mapuche. 1880 a 1978” en Pablo Mariman et al., i...Escucha, Winka...! Cuatro ensayos de historia nacional mapuche y un epílogo sobre el futuro, LOM Ediciones, Santiago de Chile, pp. 129-217.

Chihuailaf, E. (1999), Recado confidencial a los chilenos, LOM Editores, Santiago de Chile.

Chiodi, F. y Loncón, E. (1999), Crear nuevas palabras, Pillán, Temuco.

Correa, M. y Mella, E. (2010), Las razones del illkun / enojo. Memoria, despojo y criminalización en el territorio mapuche de Malleco, LOM Editores, Santiago de Chile.

Correa, S. (2011), Con las riendas del poder, Random House Mondadori, Santiago de Chile.

Del Cairo, C. y Rozo, E. (2006), “Políticas de identidad, ciudadanía intercultural y reivindicaciones territoriales indígenas en dos localidades amazónicas”, en Revista Universitas Humanísticas, Nº 61, pp. 107-134.

Donoso, A. (2008), Educación y nación al sur de la frontera. Organizacio- 
nes mapuche en el umbral de nuestra contemporaneidad, 1880-1930, Pehuén Editores, Santiago de Chile.

Espinoza, V. (2010), “Redes de poder y sociabilidad en la elite política chilena. Los parlamentarios 1990-2005”, en Polis, Universidad Bolivariana, Santiago de Chile, Vol. 9, № 26, pp. 215-286.

Foerster, R. y Montecino, S. (1988), Organizaciones, lideres y contiendas mapuches (1900-1970), CEM, Santiago de Chile.

Fornet-Betancourt, R. (2002), "Filosofía e interculturalidad en América Latina: intento de introducción no filosófica”, en González, G. (coord.), El discurso intercultural. Prolegómenos a una filosofía intercultural, Biblioteca Nueva, Madrid.

Kymlicka, W. (1996), Ciudadanía multicultural. Una teoría liberal de los derechos de las minorías, Paidós, Barcelona.

Levil, R. (2006), “Sociedad mapuche contemporánea”, en Pablo Mariman et al., i...Escucha, Winka...! Cuatro ensayos de historia nacional mapuche y un epílogo sobre el futuro, LOM Ediciones, Santiago de Chile, pp.219252.

Marimán, P. (2006), “Los mapuche antes de la conquista militar chilenoargentina”, en Pablo Mariman et al., i...Escucha, Winka...! Cuatro ensayos de historia nacional mapuche y un epílogo sobre el futuro, LOM Ediciones, Santiago de Chile, pp.53-127.

Marimán, J. “Del Estado uninacional y monocultural al Estado plurinacional y multicultural” en http://eldesconcierto.cl/del-estado-uninacional-ymonocultural-al-estado-plurinacional-y-multicultural/ junio 2014.

Mead, G.H. (1973), Espíritu, persona y sociedad. Paidós Ibérica, Barcelona.

Millalén, J. (2006), “La sociedad mapuche prehispánica: Kimün, arqueología y etnohistoria” en Pablo Mariman et al., i...Escucha, Winka...! Cuatro ensayos de historia nacional mapuche y un epílogo sobre el futuro, LOM Ediciones, Santiago de Chile, pp. 17- 52.

Mouffe, Ch. (1999), El retorno de lo político. Comunidad, ciudadanía, pluralismo, democracia radical. Barcelona: Paidós.

Saiz, J., Rapimán, E. y Mladinic, A. (2008), “Estereotipos sobre los mapuche: reciente evolución”, en Psykhe, Vol. 17, N 2, pp. 27-40.

Salas, R. (2003), Ética intercultural. (Re) lecturas del Pensamiento latinoamericano, Eds. UCSH, Santiago de Chile. 
Polis, Revista Latinoamericana, Volumen 14, $N^{\circ}$ 41, 2015

Salazar, G. y Pinto, J. (1999), Historia contemporánea de Chile, vol. I y II. LOM Editores, Santiago de Chile.

Samaniego, A. y Ruiz C. (2007), Mentalidades y políticas wingka: pueblo mapuche, entre golpe y golpe (de Ibáñez a Pinochet). CSIC, Madrid.

Taylor, Ch. (2003) “Nacionalismo y modernidad” pp. 53-86. En: McKim, R. y J. McMahan, 2003, La moral del nacionalismo. Dilemas identitarios en la era de la globalización. Barcelona: Gedisa.

Todorov, T. (2005), Nosotros y los otros, Siglo XXI Editores, México - DF.

Todorov, T. (2007), La conquista de América. El problema del otro, Siglo XXI Editores, México - DF.

Tugendhat, E. (2002), Problemas, Gedisa, Barcelona.

Zapata, C. (2005), “Origen y función de los intelectuales indígenas”, en Cuadernos Interculturales, Universidad de Valparaíso, Ano 3, Nº 4.

Zizek, S. (2003), "Passion In The Era of Decaffeinated Belief”, en The Symptom, Issue 5, online: http://www.lacan.com/passionf.htm

Zizek, S. (2001), “The One Measure of True Love is: You Can Insult the Other”, en Slavoj •i•ek, Interviewed by Sabine Reul and Thomas Deichmann, online: http://www.spiked-online.com/Articles/00000002D2C4.htm.

Recibido: 15.04.2014

Aceptado:10.10.0214 